\title{
miR-608 rs4919510 C>G POLYMORPHISM DECREASED THE RISK OF BREAST CANCER IN AN IRANIAN SUBPOPULATION
}

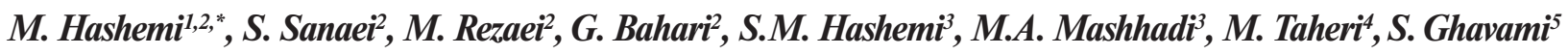 \\ ${ }^{1}$ Cellular and Molecular Research Center, Zahedan University of Medical Sciences, Zahedan 98167-431758, \\ Iran \\ ${ }^{2}$ Department of Clinical Biochemistry, School of Medicine, Zahedan University of Medical Sciences, \\ Zahedan 98167-431758, Iran \\ ${ }^{3}$ Department of Internal Medicine, School of Medicine, Zahedan University of Medical Sciences, \\ Zahedan 98167-431758, Iran \\ ${ }^{4}$ Genetic of Non-Communicable Disease Research Center, Zahedan University of Medical Sciences, \\ Zahedan 98167-431758, Iran \\ ${ }^{5}$ Department of Human Anatomy and Cell Science, College of Medicine, Faculty of Health Sciences, \\ University of Manitoba, Winnipeg, Manitoba R3E 0J9, Canada
}

\begin{abstract}
Aim: MicroRNAs (miRNAs) are small noncoding RNAs that function as oncogene or tumor suppressors. The single nucleotide polymorphisms in miRNAs potentially can alter miRNA-binding sites on target genes as well as affecting miRNAs expression. The present study aimed to evaluate the impact of miR-608 rs4919510 C $>$ G variant on breast cancer (BC) risk. Materials and Methods: This case-control study conducted on 160 women with $\mathrm{BC}$ and 192 age-matched healthy women. Genotyping of miR608 rs4919510 was done using polymerase chain reaction-restriction fragment length polymorphism (PCR-RFLP) method. Results: Our findings showed that GC genotype significantly decreased the risk of $\mathrm{BC}$ (odds ratio $(\mathrm{OR})=0.49,95 \%$ confidence interval (CI) $0.28-0.88, \mathrm{p}=0.018)$ compared to $\mathrm{CC}$ genotype. Furthermore the $\mathrm{G}$ allele decreased the risk of $\mathrm{BC}(\mathrm{OR}=0.53$, $95 \% \mathrm{CI} 0.30-0.92, \mathrm{p}=0.024)$. No significant association was found between miR-609 genotypes and clinicopathological characteristics of BC patients $(p>0.05)$. Conclusion: Our findings indicate that miR-608 polymorphism might be associated with decreased risk of BC in an Iranian subpopulation. Further large-scale studies with different ethnicities are needed to verify our findings. Key Words: miR-608, breast cancer, polymorphism.
\end{abstract}

Breast cancer (BC) is one of the most prevalent types of cancer in women. It is a major public and global health problem and accounts for $14 \%$ of total cancer deaths worldwide annually [1]. Similarly, BC is among the most common malignancies amongst Iranian women [2]. Although causes of $\mathrm{BC}$ are not yet completely understood, genetic factors are indicated to play key roles in the pathogenesis and progress of this malignancy [3-8].

MicroRNAs (miRNAs) are a highly conserved class of small ( 22 nucleotides), endogenous, non-coding RNAs suppressing posttranscriptional gene expression by base pairing with their target messenger RNAs (mRNAs) and inducing either translational repression or mRNA degradation [9-11]. Loss of heterozygosity in the 10q24 locus has been described in numeral of human cancers [12-15]. Hsa-mir-608 lies within an intron of SEMA4G in this region. Several single nucleotide polymorphisms in the sequences of premiRNAs such as miR-196a2 ( $r s 11614913 \mathrm{~T}>\mathrm{C}$ ), miR499 ( $r s 3746444 A>G)$, and miR-125a (rs12975333 G > T) were associated with significantly increased risks of $B C$ in some but not all studies [7, 16-18].

It has been proposed that $r 4919510 \mathrm{C}>\mathrm{G}$ variant in miR-608 can alter its binding to target genes [19]. The expected targets of miR-608 include insulin recep-

Submitted: January 07, 2016.

*Correspondence: E-mail: hashemim@zaums.ac.ir

Abbreviation used: $\mathrm{BC}$ - breast cancer; $\mathrm{Cl}$ - confidence interval;

miRNAs - microRNAs; mRNAs - messenger RNAs; OR - odds ratio. tor (INSR), interleukin-1 alpha (IL1A), growth hormone receptor (GHR), and TP53 [19].

Several studies examined the impact of miR608 rs4919510 C>G on the risk of various cancers, but the results were inconsistent [20-26]. To the best of our knowledge, limited studies evaluated association between miR-608 rs4919510 polymorphism and $\mathrm{BC}$ risk $[21,27,28]$. So, this case-control study was designed to assess the possible association between miR-608 rs4919510 polymorphism and susceptibility to $\mathrm{BC}$ in an Iranian subpopulation.

\section{MATERIALS AND METHODS}

This case-control study was done on $160 \mathrm{BC}$ patients and 192 age-matched healthy women with no history of cancer of any type (as the control group) in Zahedan, southeast Iran. Ethical approvals for recruitment were taken from local Ethics Committee of Zahedan University of Medical Sciences, and informed consent was obtained from all patients and healthy individuals. The study design and enrolment procedure were described previously [29-31].

Genotyping of miR-608 rs4919510 C > G was done by PCR-RFLP methods. Briefly, forward and reverse primers were $5^{\prime}$-TCTGGCTAGGTAATGGCTCC- $3^{\prime}$ and 5'-GCATCTGTGGCCTTCCATGA-3', respectively. The PCR product was digested by Pvull restriction enzyme (Fermentas). G allele digested and produced 242-bp and 117-bp pattern, while $C$ allele undigested and produced 359-bp fragment (Figure). 


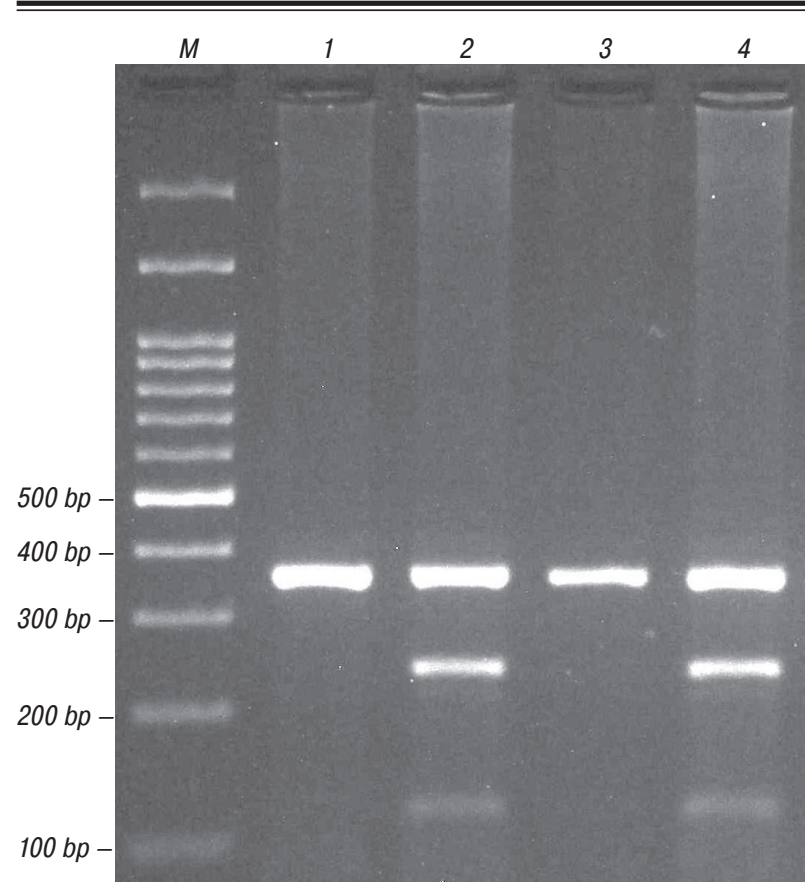

Figure. Photograph of miR608 rs4919510 C > G polymorphism using PCR-RFLP method. G allele digested by Pvull restriction enzyme and produced 242-bp and 117-bp pattern, while $C$ allele was undigested (359-bp fragment). M - DNA marker; lanes 1 and $3-\mathrm{CC}$; lane 2 and $4-\mathrm{CG}$

Statistical analysis. Statistical analysis was done using statistical package SPSS 20 software. The categorical and continuous data were analyzed using $\mathrm{X}^{2}$ and $\mathrm{t}$-test, respectively. The association between genotypes and $\mathrm{BC}$ were assessed by computing the odds ratio $(\mathrm{OR})$ and $95 \%$ confidence intervals $(\mathrm{Cl})$ from logistic regression analyses. A $p$-value of $<0.05$ was considered to be statistically significant.

\section{RESULTS}

The study group consisted of $160 \mathrm{BC}$ patients with an average age of $48.5 \pm 10.8$ years and 192 healthy women with a mean age of $49.5 \pm 12.4$ years. No significant difference was found between the groups regarding age $(p=0.424)$.

The genotype and allele frequencies of miR608 rs4919510 C>G polymorphism in BC patients and healthy women are shown. Our findings showed that rs4919510 variant significantly decreased the risk of BC (OR $=0.49,95 \% \mathrm{Cl} 0.28-0.88, \mathrm{p}=0.018, \mathrm{CG}$ vs CC) (Table 1). Moreover, the G allele significantly decreased the risk of $\mathrm{BC}(\mathrm{OR}=0.53,95 \% \mathrm{Cl} 0.30-0.92, \mathrm{p}=0.024)$ compared with $\mathrm{C}$ allele. No significant association was found between miR-609 genotypes and clinicopathological characteristics of BC patients $(p>0.05)$.

Table 1. Association of miR-608 rs4919510 C > G polymorphism and risk of $\mathrm{BC}$

\begin{tabular}{|c|c|c|c|c|}
\hline $\begin{array}{c}\operatorname{miR608} \\
\text { rs4919510 C>G }\end{array}$ & Case, $n$ (\%) & $\begin{array}{c}\text { Control, } \\
\mathrm{n}(\%)\end{array}$ & OR (95\% Cl) & $\mathrm{p}$ \\
\hline $\mathrm{CC}$ & $140(875)$ & Genotype & 100 & - \\
\hline $\mathrm{GC}$ & $20(12.5)$ & $43(22.4)$ & $0.49(0.28-0.88)$ & 0.018 \\
\hline GG & $0(0.0)$ & $\begin{array}{l}0(0.0) \\
\text { Allele }\end{array}$ & $0.700-$ & - \\
\hline C & 300 (93.8) & 341 (88.8) & 1.00 & - \\
\hline G & $20(6.2)$ & $43(11.2)$ & $0.53(0.30-0.92)$ & 0.024 \\
\hline
\end{tabular}

Hardy - Weinberg equilibrium (HWE) was assessed by chi-square test. The genotype of miR608 rs4919510 polymorphism in both controls and cases were in HWE $\left(X^{2}=3.05, p=0.081\right.$ and $\chi^{2}=0.71$, $p=0.399$, respectively).

As shown in Table 2, miR-608 rs4919510 polymorphism was not associated with clinicopathological characteristics, including age, tumor size, tumor stage, tumor grade, lymph node metastasis, estrogen and progesterone receptors (ER, PgR) status, and human epidermal growth factor receptor 2 (HER2) neu) $(p>0.05)$.

Table 2. Association between miR-608 rs4919510 C > G variant and clinicopathological characteristics of BC patients

\begin{tabular}{|c|c|c|c|}
\hline \multirow{2}{*}{ Variables } & \multicolumn{2}{|c|}{ miR-608 rs4919510 } & \multirow[b]{2}{*}{$\mathrm{p}$} \\
\hline & $\mathrm{CC}$ & CG & \\
\hline Age & & & 0.943 \\
\hline$\leqslant 50$ & 82 & 12 & \\
\hline$>50$ & 58 & 8 & \\
\hline Tumor size, $\mathrm{cm}$ & & & 0.467 \\
\hline$\leqslant 2$ & 49 & 9 & \\
\hline$>2$ & 86 & 11 & \\
\hline Lymph node metastasis status & & & 0.793 \\
\hline Yes & 83 & 13 & \\
\hline No & 39 & 5 & \\
\hline Grade & & & 0.811 \\
\hline I & 23 & 4 & \\
\hline II & 71 & 10 & \\
\hline III + IV & 19 & 4 & \\
\hline Stage & & & 0.994 \\
\hline 1 & 24 & 3 & \\
\hline II & 55 & 8 & \\
\hline III & 39 & 6 & \\
\hline IV & 21 & 3 & \\
\hline Histology & & & 0.611 \\
\hline Ductal carcinoma & 91 & 12 & \\
\hline Others & 43 & 8 & \\
\hline ER & & & 0.799 \\
\hline Positive & 82 & 12 & \\
\hline Negative & 50 & 6 & \\
\hline $\mathrm{PgR}$ & & & 0.311 \\
\hline Positive & 78 & 8 & \\
\hline Negative & 54 & 10 & \\
\hline HER2/neu & & & 0.244 \\
\hline Positive & 74 & 7 & \\
\hline Negative & 65 & 12 & \\
\hline
\end{tabular}

\section{DISCUSSION}

In the present study we inspected the impact of miR-608 rs4919510 variant on the risk of BC risk in a sample of Iranian population. Our data showed that rs4919510 polymorphism significantly decreased the risk of $B C$ in our population. We found no significant association between miR-608 rs4919510 genotypes and clinicopathological characteristics of BC patients $(p>0.05)$.

Huang et al. [27] identified that the mir608 rs4919510 was not associated with BC risk, but CG/GG genotypes were specifically associated with increased risk of HER2-positive BC (OR $=1.97,95 \%$ $\mathrm{Cl}$ 1.34-22.90). Variant $\mathrm{G}$ allele was the risk allele with OR of 1.62 (95\% Cl 1.23-22.15). They found that patients carrying GG-genotype also had larger HER2positive tumors. They concluded that rs4919510 polymorphism in mature miR-608 may influence HER2positive BC risk and proliferation of tumor. Jiao et al. [21] have found no significant association between miR-608 rs4919510 polymorphism and BC survival in Chinese population. Dai et al. [28] observed that miR-608 rs4919510 was not associated with BC risk. 
In summary, our findings proposed that miR608 rs4919510 polymorphism decreased the risk of BC in a sample of Iranian population. However, we found no significant association between this variant and the clinicopathological characteristics of BC patients. Population based studies with larger sample sizes with different ethnicities and long-term follow-up are required to confirm our finding.

\section{ACKNOWLEDGEMENT}

This paper was funded by a research grant from the Deputy for Research, Zahedan University of Medical Sciences.

\section{CONFLICTING INTERESTS}

The Authors declare that there is no conflict of interest to disclose.

\section{REFERENCES}

1. Jemal A, Bray F, Center MM, et al. Global cancer statistics. CA Cancer J Clin 2011; 61: 69-90.

2. Harirchi I, Kolahdoozan S, Karbakhsh M, et al. Twenty years of breast cancer in Iran: downstaging without a formal screening program. Ann Oncol 2011; 22: 93-7.

3. Hashemi M, Fazaeli A, Ghavami S, et al. Functional polymorphisms of FAS and FASL gene and risk of breast cancer - pilot study of 134 cases. PloS One 2013; 8: e53075.

4. Hashemi M, Eskandari-Nasab E, Fazaeli A, et al. Association between polymorphisms of glutathione S-transferase genes (GSTM1, GSTP1 and GSTT1) and breast cancer risk in a sample Iranian population. Biomark Med 2012; 6: 797-803.

5. Hashemi M, Eskandari-Nasab E, Fazaeli A, et al. Bidirectional PCR allele-specific amplification (bi-PASA) for detection of caspase- $8-6526 \mathrm{~N}$ ins/del promoter polymorphism (rs3834129) in breast cancer. Gene 2012; 505: 176-9.

6. Eskandari-Nasab E, Hashemi M, Rezaei H, et al. Evaluation of UDP-glucuronosyltransferase 2B17 (UGT2B17) and dihydrofolate reductase (DHFR) genes deletion and the expression level of NGX6 mRNA in breast cancer. Mol Biol Rep 2012; 39: 10531-9.

7. Omrani M, Hashemi M, Eskandari-Nasab E, et al. hsa-mir-499 rs3746444 gene polymorphism is associated with susceptibility to breast cancer in an Iranian population. Biomark Med 2014; 8: 259-67.

8. Amininia S, Hashemi M, Ebrahimi M, et al. Association between CCNE1 polymorphisms and the risk of breast cancer in a sample of southeast Iranian population. Medical Oncol 2014; 31: 189.

9. Bartel DP. MicroRNAs: genomics, biogenesis, mechanism, and function. Cell 2004; 116: 281-97.

10. Esquela-Kerscher A, Slack FJ. Oncomirs - microRNAs with a role in cancer. Nat Rev Cancer 2006; 6: 259-69.

11. Lynam-Lennon N, Maher SG, Reynolds JV. The roles of microRNA in cancer and apoptosis. Biol Rev Camb Philos Soc 2009; 84: 55-71.

12. Bashyam MD, Bair R, Kim YH, et al. Array-based comparative genomic hybridization identifies localized DNA amplifications and homozygous deletions in pancreatic cancer. Neoplasia 2005; 7: 556-62.

13. Daido S, Takao S, Tamiya T, et al. Loss of heterozygosity on chromosome 10q associated with malignancy and prognosis in astrocytic tumors, and discovery of novel loss regions. Oncol Rep 2004; 12: 789-95.
14. Kim JH, Dhanasekaran SM, Mehra R, et al. Integrative analysis of genomic aberrations associated with prostate cancer progression. Cancer Res 2007; 67: 8229-39.

15. Wang X, Zbou C, Qiu G, et al. Screening of new tumor suppressor genes in sporadic colorectal cancer patients. Hepatogastroenterology 2008; 55: 2039-44.

16. Hu Z, Liang J, Wang Z, et al. Common genetic variants in pre-microRNAs were associated with increased risk of breast cancer in Chinese women. Hum Mutat 2009; 30: 79-84.

17. Li W, Duan R, Kooy F, et al. Germline mutation of microRNA-125a is associated with breast cancer. J Med Genet 2009; 46: 358-60.

18. Peterlongo P, Caleca L, Cattaneo E, et al. The rs12975333 variant in the miR-125a and breast cancer risk in Germany, Italy, Australia and Spain. J Med Genet 2011; 48: 703-4.

19. Landi D, Gemignani F, Barale R, et al. A catalog of polymorphisms falling in microRNA-binding regions of cancer genes. DNA Cell Biol 2008; 27: 35-43.

20. Wei WJ, Wang YL, Li DS, et al. Association study of single nucleotide polymorphisms in mature microRNAs and the risk of thyroid tumor in a Chinese population. Endocrine 2015; 49: 436-44.

21. Jiao L, Zhang J, Dong Y, et al. Association between miR-125a rs12976445 and survival in breast cancer patients. Am J Transl Res 2014; 6: 869-75.

22. Kupcinskas J, Bruzaite I, Juzenas S, et al. Lack of association between miR-27a, miR-146a, miR-196a-2, miR492 and miR-608 gene polymorphisms and colorectal cancer. Scient Rep 2014; 4: 5993.

23. Lin M, Gu J, Eng C, et al. Genetic polymorphisms in microRNA-related genes as predictors of clinical outcomes in colorectal adenocarcinoma patients. Clin Cancer Res 2012; 18: 3982-91.

24. Ryan BM, McClary AC, Valeri N, et al. rs4919510 in hsamir-608 is associated with outcome but not risk of colorectal cancer. PloS One 2012; 7: e36306.

25. Wang R, Zhang J, Ma Y, et al. Association study of miR149 rs2292832 and miR608 rs4919510 and the risk of hepatocellular carcinoma in a largescale population. Mol Med Rep 2014; 10: 2736-44.

26. Zhang P, Wang J, Lu T, et al. miR-449b rs10061133 and miR-4293 rs12220909 polymorphisms are associated with decreased esophageal squamous cell carcinoma in a Chinese population. Tumour Biol 2015; 36: 8789-95.

27. Huang AJ, Yu KD, Li J, et al. Polymorphism rs4919510:C $>\mathrm{G}$ in mature sequence of human microRNA-608 contributes to the risk of HER2-positive breast cancer but not other subtypes. PloS One 2012; 7: e35252.

28. Dai ZM, Kang HF, Zhang WG, et al. The associations of single nucleotide polymorphisms in miR196a2, miR-499, and miR-608 with breast cancer susceptibility: A STROBECompliant Observational Study. Medicine 2016; 95: e2826.

29. Hashemi M, Amininia S, Ebrahimi M, et al. Association between $h T E R T$ polymorphisms and the risk of breast cancer in a sample of Southeast Iranian population. BMC Res Notes, 2014. 895 p.

30. Hashemi M, Sanaei S, Mashhadi MA, et al. Association study of hsa-mir-603 rs11014002 polymorphism and risk of breast cancer in a sample of Iranian population. Cell Mol Biol (Noisy-le-grand) 2015; 61: 69-73.

31. Hashemi M, Yousefi J, Hashemi SM, et al. Association between programmed cell death 6 interacting protein insertion/ deletion polymorphism and the risk of breast cancer in a sample of Iranian Population. Dis Markers 2015; 2015: 854621. 